\title{
TAXONOMIA DA REPRESENTAÇÃO EM DESIGN
}

\section{TAXONOMY IN DESIGN REPRESENTATION}

\author{
Airton Cattani ${ }^{1}$ \\ Jacques Leenhardt ${ }^{2}$
}

\begin{abstract}
Resumo
Um dos requisitos fundamentais para a existência de qualquer objeto produzido na moderna sociedade industrial é a possibilidade de ser representado, ou seja, existir previamente por meio de modelos que contenham informações sobre ele e que respondam adequadamente às necessidades de cada etapa de sua concepção, produção, divulgação e consumo. Para dar conta dessa representação, uma série de recursos pode ser empregada, variando dos mais precisos aos mais abstratos. Conhecer as peculiaridades destes recursos é fundamental para que se obtenha melhor aproveitamento na comunicação e divulgação da produção em design. Após uma contextualização da representação em design, identificando suas possibilidades e limites, este artigo propõe o estabelecimento de categorias de classificação e análise dos diferentes sistemas de representação, agrupados sob características comuns. De cunho didático e analítico, esta classificação procura contribuir tanto para o melhor entendimento e aproveitamento dos diversos recursos comunicacionais do design, refletindo sobre o estado da arte em termos de representação, quanto para a consolidação de uma teoria do design.
\end{abstract}

Palavras-chave: representação em design; comunicação em design; taxonomia.

\begin{abstract}
One of the fundamental requirements for the existence of any object produced in modern industrial society is the possibility that it can be be represented, or that already exist through templates that contain information about it and rightly responds to the needs of each stage of its design, production, dissemination and consumption. To account for this representation, a number of features can be used, ranging from more accurate to the more abstract. Knowing the peculiarities of these resources is essential in order to obtain better use of communication and dissemination of the production in design. After the contextualization of representation in design, identifying their possibilities and limitations, this article proposes the establishment of categories of classification and analysis of the different systems of representation, grouped under common characteristics. Didactic and analytical, this classification seeks to contribute both to the better understanding and use of various communication features of design, reflecting on the state of the art in terms of representation, and for the consolidation of a theory of design.
\end{abstract}

Keywords: representation in design; communication in design; taxonomy.

\footnotetext{
1 Professor Doutor, Departamento de Design e Expressão Gráfica, UFRGS, Porto Alegre. aacc@ufrgs.br

2 Professor Doutor, École d'hautes études en sciences sociales, EHESS, Paris. jacques.leenhardt@erhess.fr
} 


\section{Introdução}

Tornar presente uma realidade futura por intermédio de uma representação não é fazer acreditar que ela esteja diante de nós, mas mostrar suas características de outra maneira ${ }^{3}$. (DURAND, 2003, p. 14)

A complexidade dos projetos em design sempre foi um desafio para seus autores. Excetuandose anônimos projetistas detentores de um saber empírico ou vernacular transmitido de geração a geração, que praticamente dispensam a antecipação ou qualquer tipo de representação, via de regra os profissionais dotados de um conhecimento sistematizado sobre questões projetuais, formais, conceituais, metodológicas, estruturais e de produção não podem abrir mão de recursos que permitam antever as características do objeto proposto. Isto implica em que um dos requisitos fundamentais para a existência dos objetos projetados sobretudo a partir do momento em que os processos produtivos tornaram-se mais complexos - é a possibilidade de serem representados, ou seja, existirem previamente por meio de um modelo (gráfico ou físico, bi ou tridimensional) que contenha informações sobre o objeto e que responda adequadamente às necessidades de cada etapa de sua produção e consumo. Será por meio deste modelo que serão mostradas as características do objeto e compreendidas suas articulações formais, conceituais e estruturais, bem como será possível definir o processo produtivo que culminará na sua existência concreta. Representar revela-se, assim, uma condição incontornável e insubstituível para a existência não só dos produtos projetados no âmbito do design, mas para a maioria dos campos de conhecimento cuja expressão resulte em objetos concretos. Neste sentido, sistematizar o conhecimento em termos de recursos de representação em design se faz necessário, sobretudo quando se tem em mente a quantidade e variedade de meios e modos de representar disponíveis na contemporaneidade. Conhecer esses recursos e analisá-los de forma crítica permitirá seu uso mais refletido e consciente por parte de designers e usuários, que assim poderão explorar com maior propriedade suas possibilidades e limites.

Este artigo contextualiza a representação em design, enfocando suas principais funções como antecipadoras de uma realidade. Em um segundo momento, investiga as possibilidades e limites da representação para, finalmente, propor uma taxonomia na qual seja possível localizar os diferentes recursos disponíveis atualmente para antecipar um objeto a ser produzido ou mesmo existente. A adequada compreensão destes recursos em diferentes contextos possibilitará uma comunicação de qualidade no âmbito do design.

\section{Funções da Representação em Design ${ }^{4}$}

Etimologicamente representar provém do latim repraesentatio, de repraesentare, que significa tornar presente (de presens: presente) algo que está ausente. É estar em lugar de, substituir, reproduzir algo. Ou seja, não estar em presença de um original e sim de um substituto que se

\footnotetext{
${ }^{3}$ No original: Rendre présente une réalité à venir par l'intermédiaire d'une représentation, ce n'est pas faire croire qu'elle est devant nous, mais c'est dire autrement ce qu'elle recèle. Tradução dos autores.

4 Ao tratar de representação, diversos significados podem ser evocados, desde os abstratos, associados a significados sociais, intelectuais ou culturais, até os de existência concreta. A análise aqui desenvolvida se centrará nestes últimos, investigando o caráter documental ou imagético, ou seja, o aspecto visível e objetivo que participa direta, técnica e culturalmente dos modos de produção e consumo do design na contemporaneidade.
} 
parece ou faz referência a ele. Outras definições podem contribuir para esclarecer este conceito: ser a imagem ou a reprodução de algo; estar em lugar de; substituir; aparecer em outra forma; reproduzir, descrever; simbolizar; expor por palavras ou por escrito; figurar como símbolo; tornar presente; tornar visível; evocar; significar; desempenhar o papel, as atribuições, a função de; figurar como; simular.

Assim, sempre que estivermos nos referindo à representação de um objeto, estaremos nos referindo a ele de uma maneira indireta, frente a algo que apenas lhe diz respeito e nos comunica suas características sem ser exatamente ele, pois entre os objetivos da representação não está o de substituir plenamente o objeto representado e a experiência direta que advém da interação que se estabelece com ele.

Para Cocchiarella (2010, p. 134), a representação manteve ao longo dos séculos seu antigo e pregnante significado de realidade intermediária entre o campo abstrato das ideias e dos conceitos e o campo concreto do mundo físico, atuando como mediadora entre a ideia e o objeto. Além de tema prioritário, quando se fala em design, Bistagnino (2010, p. 20) considera o conhecimento dos sistemas de representação fundamental para a formação do designer. Afirma o autor que o estudo do caráter conceitual do design é necessário e preliminar à adequada aprendizagem dos conteúdos científicos de sua práxis. Já Baudoin $(2016$, p. 2) entende a representação como uma espécie de filtro, pois reduz a totalidade de um determinado contexto de modo que seja possível perceber algo transcendente, além da própria informação. Em outras palavras, a representação estaria imbuída de "um jeito crítico de ver", que colocaria em evidência certos aspectos do que está sendo representado pelo autor da representação.

Neste momento uma pergunta se impõe. Por que representar? Qual a necessidade de referenciar algo - o objeto - por intermédio de outro instrumento ou recurso? Para Bertin (1998), as três funções da representação são:

- registrar a informação; criar uma memória artificial para evitar o esforço de memorização. É inventariar, torná-la acessível a outros (p. 160);

- comunicar a informação; criar um conjunto memorizável de informações, inscrevendo-as em um corpo de conhecimentos adquiridos. É a mensagem que se quer transmitir (p. 162);

- tratar (dar significado) a informação; ordenar e categorizar para descobrir os agrupamentos contidos; na informação tratada, deduzir os componentes ou categorias novas (em número reduzido e, portanto, mais fácil de memorizar que uma informação exaustiva). É tornar a mensagem inteligível (p. 164).

Preocupar-se com o atendimento destas três funções, baseadas em regras que Bertin chamou de Semiologia Gráfica, permitirá determinar qual a melhor forma de transcrever uma informação, estabelecendo correspondências entre o visível e os conteúdos dessa informação. Bertin afirma (p. VII) que o principal problema com o qual a Semiologia Gráfica deve se preocupar é fornecer à inteligência humana uma memória artificial de qualidade, principalmente no contexto do mundo contemporâneo, onde a quantidade de informações disponíveis é incalculável. Em outras palavras, quanto mais claramente for apresentada a informação, melhores serão as condições para a sua elaboração mental e posterior compreensão. 
Baseado nas funções prescritas por Bertin sobre a representação em geral, e nas prescritas por Durand (2003, p. 11-12), ao referir-se à representação em arquitetura, é possível estabelecer as principais funções da representação do objeto, seja qual for a escala - da cidade ao parafuso, do edifício ao cartaz:

- função auxiliar no processo de projeto: substituindo momentaneamente o objeto que ainda não existe, a representação permite antecipar as características (formais, funcionais, técnicas, estéticas) e oferecer condições para operações de manipulação, buscando resolver de maneira adequada seu aspecto final;

- função comunicativa: apresentando aspectos objetivos (denotativos) e subjetivos ou sugeridos (conotativos), permite a comunicação das características tanto técnico-formais, quanto conceituais do objeto a ser produzido;

- função descritiva: permite que outros interlocutores envolvidos na materialização do objeto tenham conhecimento sobre o que e como será produzido, tornando sua existência possível.

Em síntese, a função da representação em design (por analogia, em todas as áreas que de alguma forma trabalhem com a antecipação) é exteriorizar e tornar disponível para outros uma ideia até então restrita ao intelecto do autor, como uma espécie de preâmbulo da organização formal proposta ou existente, de modo a tornar compreensíveis os diversos componentes do objeto, não apenas físicos mas também conceituais. É indispensável, pois, não apenas saber fazer, mas poder comunicar claramente o que o projetista tem em mente; seu ato mental precisa se expressar de modo que os outros possam compreendê-lo. Em tempos de produção globalizada, de trabalho multidisciplinar, de dissolução de fronteiras entre campos do conhecimento até então rigorosas, o estabelecimento de canais de comunicação efetivos e de compreensão unívoca passa necessariamente pelo entendimento comum e aproveitamento integral de formas de comunicação, nas quais a representação desempenha importante papel.

Assim, o melhor entendimento das propriedades específicas da representação permitirá a escolha do melhor recurso ou suporte para cada caso. Por meio desses recursos é possível definir antecipadamente a totalidade de um objeto, desde suas características conceituais até seus elementos mais concretos e detalhados. Como substituta momentânea de uma realidade, a representação em design é um instrumento de liberdade, pois permite ao designer investigar diversas possibilidades sem, no entanto, ser contido pelos limites impostos pelos aspectos operacionais da produção da obra e sem enfrentar consequências irreversíveis (Durand, 2003, p. 191). Será esta liberdade projetiva que permitirá verificar se uma vaga ideia, expressa por meio de algumas palavras ou de um croqui, tem qualidades para seguir adiante, e tomar forma, ou se tudo deverá ser recomeçado. A representação é um meio de comunicação que será mais eficiente na medida em que adotar recursos - referenciais, gráficos, físicos ou textuais - que possuam uma capacidade informativa de qualidade.

No campo do design, esta circunstância abre um leque de opções em termos de recursos de representação, variando desde os mais abstratos (texto, croquis, diagramas entre outros) até os mais concretos (desenhos técnicos, maquetes, protótipos), nos quais o grau de analogia 5 com a realidade é mais elevado, todos eles com variados graus de acabamento e

\footnotetext{
${ }^{5}$ No âmbito desta análise, analogia (do grego $\alpha v \alpha \lambda$ oví $\alpha$ ) será utilizada no sentido de similitude, semelhança entre coisas diferentes. Recursos de representação que fazem uso da analogia procuram descrever a realidade visível de modo mais verossímil possível. Assim, uma vista ortográfica, por exemplo, apresenta relações de analogia com o
} 
apresentação. Caberá ao projetista a escolha do sistema ou recursos mais adequados aos objetivos das diversas etapas do processo de trabalho. Embora predominem as representações gráficas analógicas, sobretudo desenhos e modelos físicos, uma série de outros recursos também pode fazer parte do repertório de expressão dos designers, constituindo um verdadeiro Sistema de Representação ${ }^{6}$, que pode ser empregado como suporte à tomada de decisões no processo de projeto e documentação do objeto. Considerando que o caráter das representações é tão variado como os próprios recursos gráfico/visuais à disposição dos projetistas, é necessário sistematizar este conhecimento.

\section{Possibilidades e Limites da Representação em Design}

O conhecimento das potencialidades e das limitações dos diversos recursos representacionais permite obter maior eficiência tanto na comunicação entre os vários usuários do trabalho de design, quanto no processo de projeto e na maneira como o objeto é pensado, percebido, registrado e divulgado. Mesmo que, a princípio, todos os modos e recursos de representação possam ser empregados em ambos os processos - comunicação e projeto -, é evidente que alguns terão maior aplicabilidade e resolutividade do que outros.

Saint-Aubin (1992, p. 15) lembra que existe uma diferença entre o projetado e o existente. Segundo o autor, no primeiro caso estaremos diante de um universo platônico, ideal, e a representação será uma espécie de impressão física protegida de todos os defeitos, um reflexo dessa situação ideal, e que, frente aos recursos computacionais existentes na contemporaneidade, isso é cada vez mais comum. Será a esta perfeição que a representação constantemente fará referência, independente das qualidades técnicas ou estéticas do objeto. Já para o existente - um objeto não mais perfeito, mas concreto e que reflete as dificuldades e restrições do processo produtivo e mesmo a degradação física a que está sujeito pelo uso - a representação terá que fazer a opção entre duas vertentes antagônicas: documentar o objeto em seu estado atual ou buscar o universo platônico e tentar "apagar" as imperfeições do objeto "real". Jungmann (1996, p. 33), por sua vez, lembra que na sociedade contemporânea a representação, além de participar do processo de criação, adquiriu outro papel importante: por sua grande difusão, as imagens do objeto - em suas diversas categorias - passaram a constituir uma cultura imagética autônoma, ou seja, passaram a tomar o lugar da obra, substituindo-a. A representação torna-se a obra, convertendo-se a obra em uma realidade inacessível ou simplesmente ignorada. As imagens legitimam o objeto, sendo a prova de sua existência, tornando-se a intermediária entre a obra e o observador. Por outro lado, a sedução das imagens passou a ser de tal ordem que se corre o risco de esquecer a obra que está atrás da imagem, sendo que a obra original muitas vezes é "dispensável", sobretudo frente aos novos e sedutores meios de representação oferecidos pela informática.

Essas considerações permitem estabelecer três premissas norteadoras das análises que se propõem a investigar o universo da representação em design:

\footnotetext{
objeto representado, observadas as variações de escala e a eliminação de uma das dimensões físicas - neste caso, a profundidade.

${ }^{6}$ Sistema será considerado no corpo desta análise como um conjunto de elementos agrupados e/ou coordenados, estruturados e organizados intelectualmente, de modo que possa ser percebida uma relação entre eles. Diferentemente do proposto por Sainz (1990, p. 27) em relação à arquitetura, que define o conjunto de signos observáveis visualmente relacionados entre si como um sistema gráfico, esta análise ampliará sistema gráfico para sistemas de representação.
} 
Premissa 1: já que qualquer objeto tridimensional não pode ser visto em sua totalidade, mas apenas em aspectos condicionados pela morfologia da visão humana, suas representações também serão condicionadas por estes limites;

Premissa 2: nenhum tipo de representação substitui plenamente a experiência de vivenciar o objeto quando este não estiver presente;

Premissa 3: toda a representação é uma aproximação, em maior ou menor grau, da realidade visível.

Para dar conta desses requisitos, o processo de projeto em design se apropria dos sistemas de representação para a simulação dos objetos que propõem produzir. Esta simulação, por sua vez, procura contornar uma contradição inerente a qualquer sistema, já apontada por Zevi (2000) e referendada por Rattenbury (2014) ao referirem-se à representação da arquitetura: nenhum tipo de representação substitui plenamente a experiência de vivenciar o espaço arquitetônico in loco, pois a arquitetura transcende as quatro dimensões, incorporando elementos físicos e dinâmicos em sua fruição, sendo esta uma experiência extremamente pessoal. No campo do design essa restrição também se aplica, embora as peculiaridades de certos sistemas de representação (modelos e protótipos, por exemplo) e as características de alguns objetos permitam uma interação de tal forma que praticamente não existe diferença entre o objeto representado e seu equivalente produzido industrialmente. Assim, as preocupações de Zevi e Rattenbury não encontram no design o mesmo nível de restrição da arquitetura. Embora não seja regra geral, a plena observação do próprio objeto, dos efeitos dos materiais e das cores, a percepção de sua inserção no ambiente e a interação com o usuário são mais facilmente observáveis e vivenciáveis, e relativamente mais comuns de ocorrer, devido ao caráter de multiplicidade e facilidade de dispersão geográfica que apresentam os produtos do design.

Mas esse cenário pode propiciar a ocorrência de outro fenômeno. Conforme o tipo de recurso empregado, corre-se o risco de tomar a cópia pelo original, com duas consequências antagônicas: a cópia não estará à altura do original ou sobrepujará o original. Com os recursos de manipulação digital de imagens, disponíveis atualmente, é necessário refletir sobre esta última situação, pois poderá nos conduzir à decepção de constatar que o original não está à altura de sua representação, assim como a viagem nem sempre é o que foi mostrado no catálogo da agência ou a mercadoria não é tão deslumbrante como a publicidade nos informa. Uma exposição fotográfica na qual os objetos sejam apresentados simultaneamente às suas imagens, por exemplo, pode nos levar à confrontação entre eles, podendo mostrar os objetos com qualidades que não Ihes são intrínsecas ao explorar as possibilidades de pontos de vista não usuais, iluminação controlada, impressão em papeis especiais e efeitos cenográficos que nem sempre estão presentes no cotidiano sob uma iluminação banal.

Assim como Jungmann (1996, p. 34) aponta para o perigo da visualização glamourosa sobre o processo de concepção da arquitetura - que poderia levar à produção de arquiteturas mais cenograficamente visíveis -, no design esta realidade também pode ocorrer, na medida em que a representação pode sobrepujar o objeto representado, ou mesmo criar a ilusão de que o objeto tem qualidades que na verdade nem sempre se mostram tão evidentes como na representação (Figura 1). 
Figura 1: Espremedor de laranjas de Philippe Starck (1990) apresentado cenograficamente (esquerda e centro) e de forma banal, junto com outros produtos em uma prateleira de loja (direita).
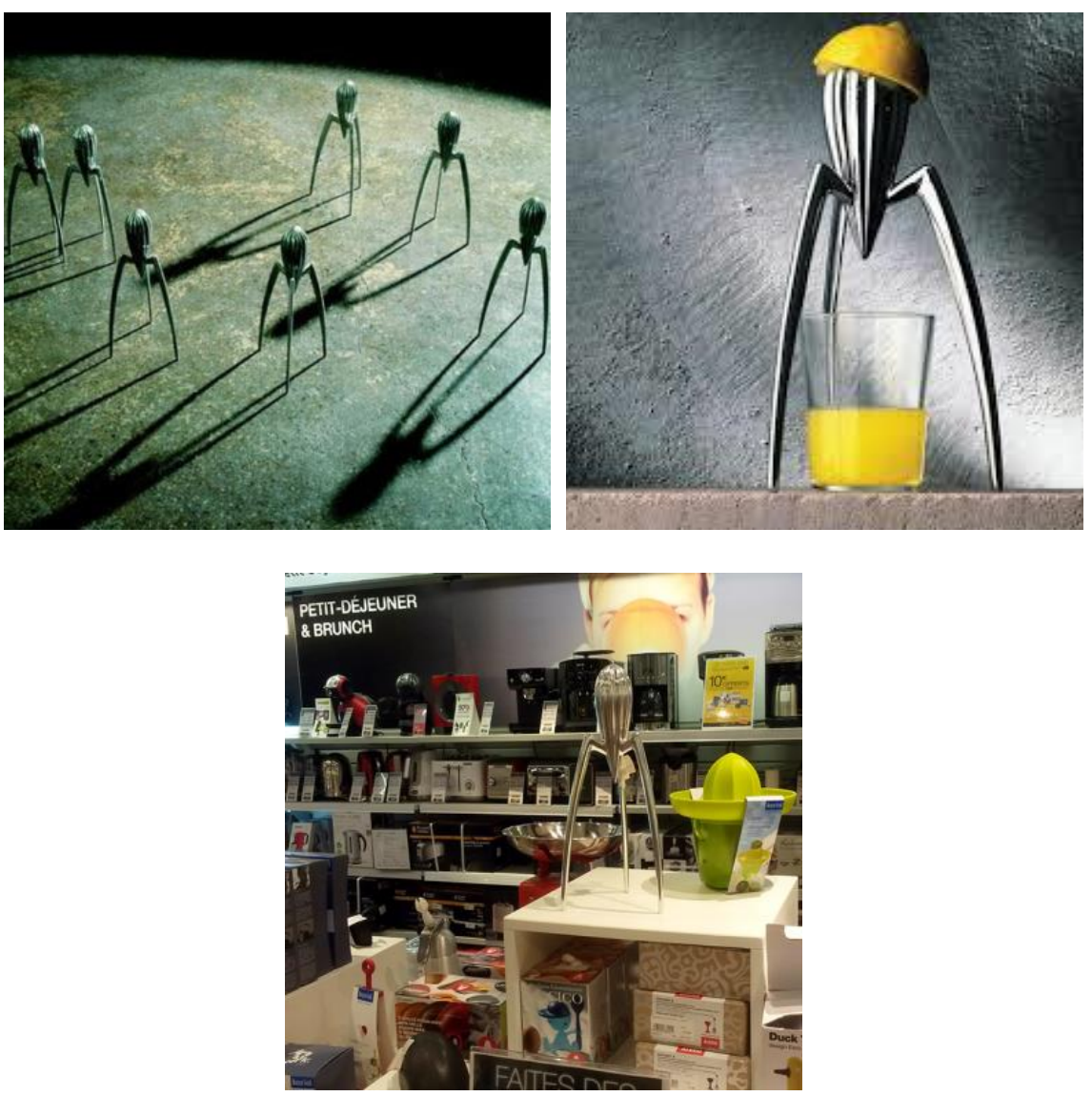

Fonte: www.starck.com (acesso em 10/02/2017), www.hivemodern.com (acesso em 10/02/2017) e acervo de Airton Cattani (2016)

\section{Sistematização dos Conhecimentos da Representação em Design}

Entendendo-se sistemas de representação como algo bem mais amplo do que apenas desenho, vários outros recursos predominantemente bi ou tridimensionais podem ser mencionados ao se falar sobre representação em design, que Deforge $(1981$, p. 12) chama de meios de representar, tais como desenhos, maquetes, filmes, simuladores, fotografias, infográficos, vídeos, textos, esquemas, gravuras, representações abstratas, palavras, gestos, entrevistas etc., cujo modo de representar poderá ser basicamente figurativo, semi-figurativo e simbólico ou abstrato.

Essa diversidade de recursos e processos destinados a compreender antecipadamente um objeto fornece subsídios não só para a preparação da intervenção física na matéria que o configurará, resolvendo problemas de natureza físico/espacial/formal por meio da atividade de projeto, mas também para a documentação de algo já existente ou das intenções conceituais do designer em relação à obra. Por outro lado, põe em evidência o caráter complexo da apreensão e compreensão de uma representação. Assim como para a compreensão do texto é necessário ter acesso aos códigos gráficos e aos significados de agrupamentos de letras estabelecidos culturalmente para se ter acesso à mensagem transmitida, com os códigos de representação de formas espaciais ocorre o mesmo: é necessário o estabelecimento de códigos e significados de entendimento comuns a todos os 
envolvidos na mensagem para que exista uma efetiva comunicação entre os atores que fazem existir o design.

Destinados a prefigurar uma realidade futura, esse conjunto de recursos constitui-se em uma verdadeira linguagem, entendida aqui no seu sentido mais amplo, dotada de características próprias e servindo para intermediar as diversas etapas do processo de trabalho e tomada de decisões de designers, bem como para a divulgação posterior de seu trabalho. Como todo pensamento sempre se exprime de forma codificada, ou seja, por meio de um sistema de signos (Bertin, 1998, p. 8), a decodificação deverá necessariamente passar pela compreensão da linguagem estabelecida. No entanto, por ser considerada tão evidente por aqueles que a utilizam cotidianamente, essa linguagem corre o risco de ser mal compreendida e interpretada por outros usuários que não a tem como expressão usual ${ }^{7}$.

Quanto à natureza dos recursos a serem empregados na representação, ela deverá responder a uma indagação proposta por Durand (2003, p. 13): trata-se simplesmente de tornar presente uma realidade ainda ausente ou de pôr em evidência o que ainda não está revelado? Para o primeiro caso, os recursos escolhidos deverão ter características de semelhança a ponto de produzir a ilusão de que o objeto esteja realmente presente, como um ícone, no qual a técnica e a maestria de representar, buscando a mais perfeita semelhança, desempenham um importante papel, sempre tendo como pano de fundo as limitações inerentes à representação; já para o segundo caso, trata-se fundamentalmente de uma atividade mental, uma vez que estarão em jogo a análise, a pesquisa, a busca e a escolha de soluções sem ter a representação uma função primordial, de apresentar algo de maneira realística. Em suma, trata-se de um mergulho do cerne do projeto, em uma trajetória permeada de interrogações, dúvidas e escolhas.

Desde o final do século $X X$, o design tem convivido com mais uma revolução em termos de recursos de representação, comparável à sistematização da representação em perspectiva no século XIV. A tecnologia da informática definiu não apenas uma nova maneira de representar os objetos, mas também contribuiu para o desenvolvimento de novas formas de projetar e ao estabelecimento de novas e peculiares características estéticas dos objetos projetados. Os avanços da informática têm permitido não apenas simulações com qualidade nunca antes imaginadas - seu aspecto mais divulgado e conhecido pelo público em geral -, mas ferramentas que permitem enfrentar e resolver rapidamente a crescente complexidade dos projetos. Com as técnicas informatizadas, os sistemas de representação adquiriram nova vitalidade e dinamismo, graças à capacidade de resumir de modo quase imediato as características dos objetos projetados. Atributos como rapidez, fidelidade, exatidão, correção e capacidade de simulação muito próxima da realidade aparente são associados a esse novo contexto tecnológico que, no entanto, nada mais faz do que utilizar os sistemas de representação desenvolvidos ao longo da história em uma nova interface ou suporte.

\section{Taxonomia da Representação em Design}

A sistematização do conhecimento em termos de representação em design - entendida no seu sentido mais amplo - procura evidenciar as potencialidades e limites de cada recurso nas

\footnotetext{
7 Para contornar esta situação e propiciar condições para que os sistemas tenham uma representação e compreensão padrão, foram estabelecidas normas técnicas (normas internacionais ISO, normas ABNT no Brasil, normas DIN na Alemanha, normas ANSI nos Estados Unidos etc.), que procuram definir formas de decodificação unívocas.
} 
diversas etapas do processo de projeto e da materialização do objeto e sua posterior divulgação. Esta representação, por seu turno, deverá ser considerada para além de uma simples ferramenta destinada a representar as ideias ou simular um objeto, mas também como ferramenta de projeto, quando esses sistemas podem fornecer subsídios para a tomada de decisões nas diferentes etapas do processo que conduz à materialização do objeto. 0 conhecimento desses sistemas, por parte do projetista, fornece repertório que permitirá a escolha do sistema mais adequado aos objetivos das diversas etapas do processo de trabalho. Nesse sentido, a sistematização pressupõe uma taxonomia ou classificação dos recursos.

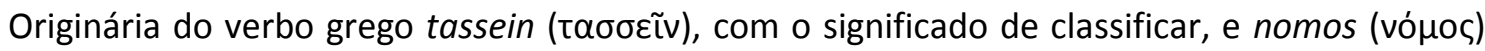
com o significado de lei ou ciência, a taxonomia é usualmente associada aos seres vivos, podendo, no entanto, ser entendida como um sistema mais abrangente de classificação ou categorização geral, aplicável a outras ciências e campos de estudo, buscando sempre maior objetividade.

Dada a diversidade e a complexidade de recursos possíveis de serem empregados na representação em design, organiza-los não é uma tarefa simples, pois todos são práticas múltiplas e interligadas com um mesmo fim: a antecipação ou registro da existência de um objeto, seja ele bi ou tridimensional. Por outro lado, o caráter intermediário a que os sistemas de representação estão associados, quando referidos ao produto final, nem sempre faz com que a representação seja encarada como algo que deva ser estudada, conservada ou divulgada.

Para dar conta da classificação dos recursos de representação no âmbito dessa análise, são propostas a seguir categorias taxonômicas que procuram agrupar os diferentes sistemas sob características comuns, baseadas nos principais meios pelos quais ocorre a comunicação em design.

Mesmo tendo em conta a multiplicidade de recursos disponíveis atualmente para representar o design, em um esforço de síntese, eles podem ser classificados em quatro categorias principais:

- oralidade: compreende a representação do design por intermédio da fala e da gesticulação;

- textos: compreendem todas as informações que utilizam a escrita como forma de descrever um objeto;

- imagens: compreendem as informações imagéticas registradas em duas dimensões;

- modelos físicos: compreendem as informações que utilizam a tridimensionalidade como forma de representar.

Estas categorias, por sua vez, podem ser divididas em subcategorias que procuram esgotar todas as possibilidades de representação em design. $O$ quadro conceitual a seguir (Figura 2) apresenta mais detalhadamente essas subcategorias. 
Figura 2: Taxonomia da representação em design.

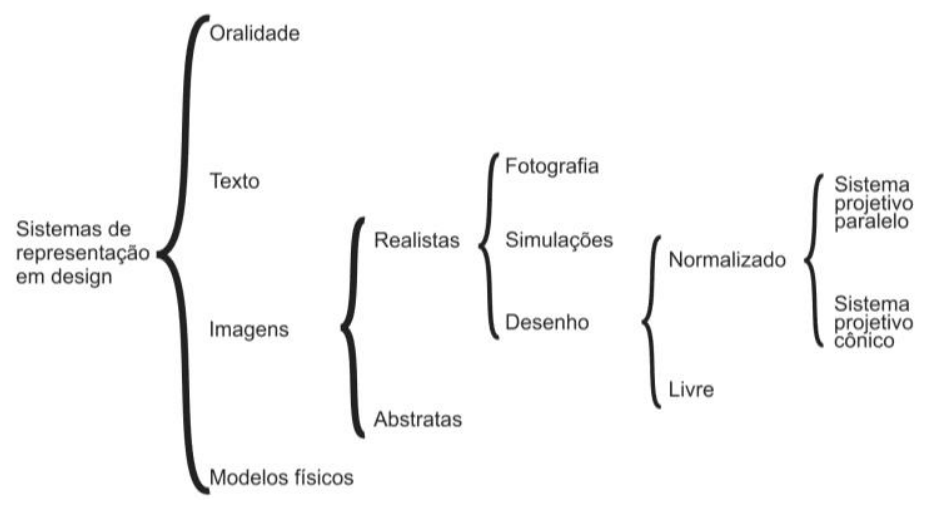

Fonte: Elaborado pelos autores.

De cunho didático e analítico, essa classificação não é estanque, ou seja, um determinado recurso pode estar presente em mais de uma categoria, tendo em vista suas peculiaridades. Assim, um desenho à mão livre pode ter características que permitem classificá-lo simultaneamente como desenho livre, mas ao mesmo tempo pode ter outras características que o definam como técnico, especulativo e normalizado, desde que empregue alguns atributos destas categorias, ao mesmo tempo em que pode empregar recursos textuais para complementar informações. Da mesma forma, um modelo físico pode fazer uso de imagens em suas superfícies.

Levando em conta a distinção entre meios de representação e modos de representação, já referidos anteriormente, essa classificação pode ser apresentada levando-se em conta as peculiaridades dos modos de representar estáticos ou dinâmicos, classificados em duas categorias:

- sistemas estáticos: compreendem as representações que se caracterizam pela imobilidade do recurso empregado, como o desenho ou o texto convencional;

- sistemas dinâmicos: compreendem os recursos nos quais a representação incorpora a dimensão tempo, como o cinema, o vídeo e a tecnologia computacional.

A Figura 3 mostra como as categorias de representação podem ter diferentes recursos como suporte.

Figura 3: Taxonomia da representação em design e suas tecnologias.

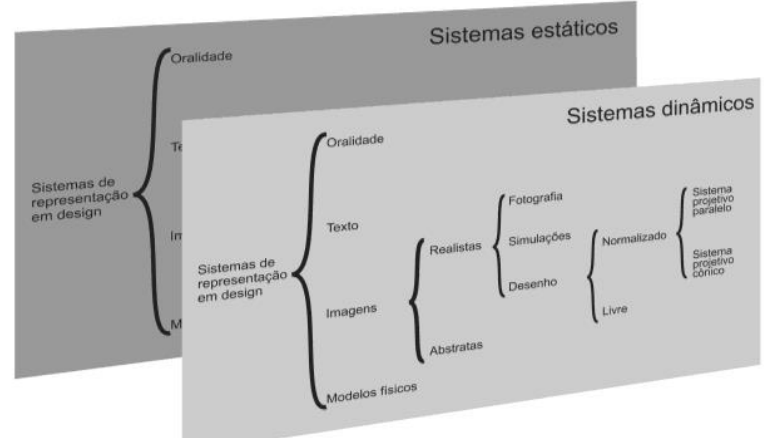

Fonte: elaborado pelos autores a partir de uma observação do prof. César Bastos de Mattos Vieira. 
Na Figura 3 é possível verificar que os modos de representar pertencem sempre a uma mesma categoria. Não haverá diferenças conceituais entre eles, mas apenas o uso de recursos que permitam maior visibilidade e interação com a informação, sobretudo no projeto de objetos tridimensionais.

A escolha do tipo de representação, por sua vez, estará diretamente vinculada às etapas básicas do projeto - entendido aqui como o percurso a ser percorrido entre a ideia e sua realização: concepção, comunicação, produção. Assim, representações mais informais e de menor definição técnica costumam ser empregadas nas etapas iniciais, quando o projeto está sendo definido, enquanto as representações mais elaboradas e de caráter mais técnico e definitivo serão utilizadas nas etapas finais, quando o projeto já está finalizado e pronto para ser produzido industrialmente. Como todas as formas de representação têm vantagens e limitações, uma efetiva comunicação em design deverá necessariamente fazer uso de múltiplas formas de expressão combinadas entre si: o desenho não poderá dispensar as informações textuais assim como os modelos físicos serão construídos tendo por base as informações fornecidas pelo desenho e assim por diante.

\section{Considerações Finais}

Você sabe melhor do que ninguém, sábio Kublai, que jamais se deve confundir uma cidade com o discurso que a descreve. Contudo existe uma ligação entre eles ${ }^{8}$. (CALVINO, 1990, p. 59.)

Ao descrever a cidade de Olívia, as palavras de Calvino nos fazem pensar sobre as possibilidades ambíguas da representação. Se, por um lado, representação e objeto - discurso e obra - são coisas distintas e nem sempre o discurso descreve o objeto de maneira fiel, por outro, guardam algum tipo de relação, refletindo assim as possibilidades simultâneas de aproximação e de diferenciação, bem como a pluralidade e diversidade deste conhecimento.

Sistematizar os conhecimentos sobre representação em design, apresentando uma proposta de taxonomia dos diversos recursos atualmente em uso para este fim, se apresenta como uma contribuição na formulação de uma teoria geral do design. Ao contrário da arquitetura, por exemplo, que tem uma vasta tradição tratadística iniciada com Vitrúvio no século I a.C., e consolidada a partir da Renascença, no design esta tradição ainda é muito recente, datando dos séculos $\mathrm{XIX}$ e $\mathrm{XX}$, o que faz com que estejamos trilhando os primeiros passos na direção de uma teorização em design, com uma diferença de centenas de anos em relação à arquitetura.

Os argumentos apresentados neste artigo pretendem demonstrar que tão importante quanto estudar a metodologia de projeto, a ergonomia, a resistência dos materiais e outros campos de conhecimento que fazem parte da formação em design em suas mais variadas ênfases ou especialidades, é estudar a representação e os meios pelos quais podemos antecipar a existência de objetos. Por apresentarem uma dupla natureza - por um lado, teórica, como pensamento materializado; por outro, como meio expressivo do próprio pensamento, como maneira de exteriorizar e tornar visível e compreensível para outros esse pensamento - os meios de representar o design se mostram como um profundo modo de conhecimento que se poder ter sobre o objeto antes dele existir efetivamente e, deste modo, poder tomar decisões que conduzam à melhores soluções.

\footnotetext{
8 No original: Nessuno sa meglio di te, saggio Kublai, che non si deve mai confondere la città col discorso che la descrive. Eppure tra l'una e l'altro c'è un rapporto. Tradução de Diogo Mainardi.
} 
Estudar a natureza dos sistemas de representação, sua história, suas formas de expressão, suas peculiaridades, a expressividade de seus códigos e as condições de uso, bem como suas contradições, pode contribuir para oferecer a todos aqueles que fazem uso da representação em design condições mais aprimoradas para sua utilização. Quanto mais consistentes forem os conhecimentos sobre a representação em design, mais qualificada será a compreensão sobre as características e peculiaridades do objeto proposto.

Finalmente, é importante salientar que o simples conhecimento e aplicação das diferentes formas de representar o objeto não significa o domínio do fazer em design, já que não se deve confundir o ofício - o design - com as ferramentas - a representação. Mais do que isso, é necessário sensibilidade, conhecimento teórico e técnico, além de um saber-fazer construído paciente e constantemente, para que se possa efetivamente fazer design empregando a representação como ferramenta, e não como fim em si. Nesse sentido, a representação cumpre um importante papel na formação dos designers, contribuindo para a estruturação tanto do repertório quanto da linguagem - formal, técnica, estética - com a qual se expressarão.

\section{Agradecimentos}

Este texto foi elaborado no contexto de estágio pós-doutoral que teve apoio do CNPq.

\section{Referências}

BAUDOIN, Genevieve S. Interpreting site. Studies in perception, representation and design. New York : Routledge, 2016.

BERTIN, Jacques. Sémiologie graphique: les diagrammes, les réseaux, les cartes. Paris: Éditions de l'EHESS, 1998.

CALVINO, Ítalo. As cidades invisíveis. São Paulo: Companhia das Letras, 1990. 1ạ ed. [Le Città invisibili, 1972]. Trad. Diogo Mainardi.

COCCHIARELLA, Luigi. Scienza e cultura nella reppresentazione per il design. In: BISTAGNINO, Enrica (Dir.). Disegno-Design: introduzione alla cultura della reppresentazione. Milano: Francoangeli, 2010.

DEFORGE, Yves. Le graphisme technique. Son histoire et son enseignement. Paris: Seyssel: Editions du Champ Vallon, 1981.

DURAND, Jean-Pierre. La représentation du projet comme instrument de conception. Aproche pratique et crtitique. Paris: Éditions de La Villete, 2003.

JUNGMANN, Jean-Paul. L'image en achitecture: de la représentation et de son empreinte utopique. Paris: Éditions de la Villette, 1996.

RATTENBURRY, Kester. (Re)présentation. Trois (ou quatre) projets (plus ou moins) récents. In : LANTENOIS, Annick ; ROUFFINEAU, Gilles (Dir.). Voir l'architecture: contribution du design à la construction des savoirs. Paris: B42, 2014.

SAINT-AUBIN, Jean-Paul. Le relevé et la représentation de l'architecture. Paris : Inventaire Général, ELP, 1992. 
SAINZ, Jorge. El dibujo de arquitectura. Teoría e historia de un lenguaje gráfico. Madrid: Reverte, 2005.

TERSTIEGE, Gerrit (Ed.). The making of design. From the model to the final product. Basel/Boston/Berlin: Birkhäuser, 2009.

ZEVI, Bruno. Saber ver a arquitetura. São Paulo: Martins Fontes, 2000. [Saper vedere l'architettura, 1948]. 